\title{
Assessment of Different Types of Domestic Violence Against Pregnant Mothers Exposed to Violence in Sahneh City
}

\section{Seyedeh Zahra Masoumi (PhD) ${ }^{1}$, Fereshteh Babahyidarian (MSc) ${ }^{2}$, Gita Sangestani $(\mathrm{PhD})^{3, *}$, Ghodratollah Roshanaei (PhD) ${ }^{4}$}

${ }^{1}$ Assistant Professor, Research center for health sciences, Hamadan University of Medical Sciences, Hamadan, Iran

${ }^{2}$ MSc, Department if Midwifery, School of Nursing and Midwifery, Hamadan University of Medical Sciences, Hamadan, Iran

${ }^{3}$ Instructor, Department if Midwifery, Hamadan University of Medical Sciences, Hamadan, Iran

${ }^{4}$ Associate Professor, Research Center For Modeling of Non-communicable Disease and Department of Epidemiology and Biostatistics, School of Public Heath, Hamadan University of Medical Sciences, Hamedan, Iran

* Corresponding Author: Gita Sangestani, Department if Midwifery, Hamadan University of Medical Sciences, Hamadan, Iran.Email: gsangesani@yahoo.com

Received: $04 / 08 / 2018$

Accepted: 19/06/2019

How to Cite this Article: Masoumi SZ, Babahyidarian F, Sangestani G, Roshanaei G. Assessment of Different Types of Domestic Violence against Pregnant Mothers Exposed to Violence in Sahneh City. Pajouhan Scientific Journal. 2019; 17(2): 24-30. DOI: 10.29252/psj.17.2.24

\section{Abstract}

Background and Objective: The high prevalence of domestic violence causes undesirable physical and mental effects on a large community of pregnant women. In addition, it can also affect the fetus health either directly or indirectly and impose tangible and intangible costs on society and the family. Hence, the present study aimed to determine different types of domestic violence against pregnant mothers.

Materials and Methods: The present research was a descriptive crosssectional study that was conducted on 92 pregnant women exposed to moderate domestic violence in Sahneh, Kermanshah Province, Iran in 2017. The participants were selected based on convenience sampling method and the data were collected using a questionnaire developed by MohseniTabrizi. The obtained data were statistically analyzed in SPSSv.16.

Results: The questionnaire data showed that the 92 women participating in this study were under moderate to severe domestic violence. Different types of domestic violence against them were as follows: emotional violence (52.29\%), psychological violence (45.9\%), verbal violence (54\%), financial violence (38.05\%), physical violence (35.96\%), sexual violence (25.7\%), and social violence (55.9\%). Therefore, the most and the least prevalent types of domestic violence against the participants are social violence and sexual violence, respectively.

Conclusion: Considering the high prevalence of different types of domestic violence against pregnant women, it is necessary to perform domestic violence screening for all pregnant women visiting health centers. In addition, development and implementation of interventions, such as life skills training and promotion of couple counselling, can be effective in the reduction of domestic violence in such families.

Keywords: Domestic Violence; Pregnant Women; Sahneh 
ميزان انواع خشونت خانكى در مادران باردار در معرض خشونت شهر ستان صحنه

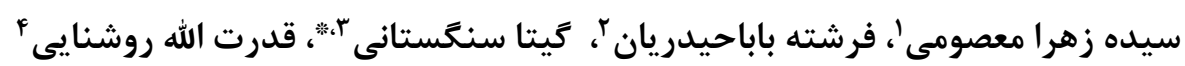

' دانشيار، مركز تحقيقات علوم بهداشتى، گروه مامايى، دانشكده يرستارى و مامايى، دانشخاه علوم يزشكى همدان، همدان، ايران

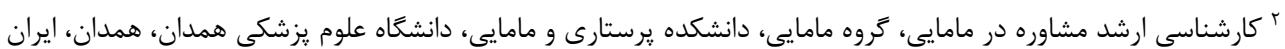

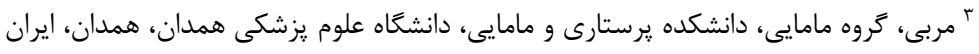

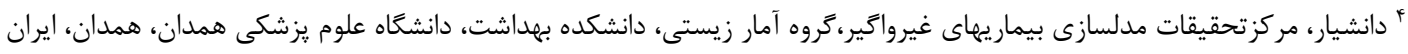
* نويسنده مسئول: گَيتا سنگستانى، گروه مامايى، دانشكده يرستارى و مامايى، دانشكاه علوم يزشكى همدان، همدان، ايران. ايميل: gsangesani@yahoo.com

\section{جكيده}

سابقه و هدف: شيوع بالاى خشونت خانكى موجب تاثيرات نامطلوب جسمى و روانى بر جامعه بزركى از زنان

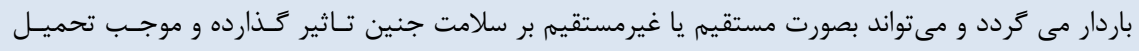

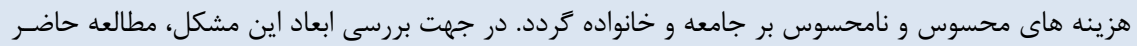
با هدف تعيين ميزان انواع خشونت خانكى در مادران بان باردار انجام شدان

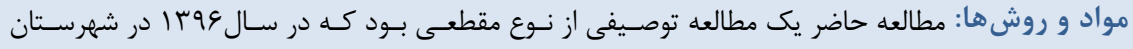

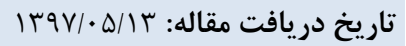

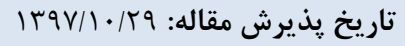
تمامى حقوق نشر براى دانشكاه علوم يزشكى همدان محفوظ است.

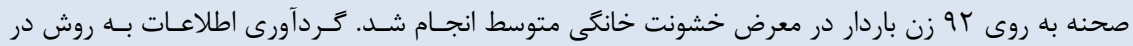

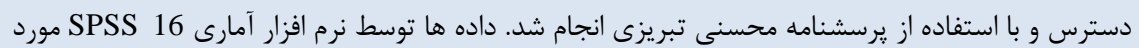
تجزيه و تحليل قرار كرفت.

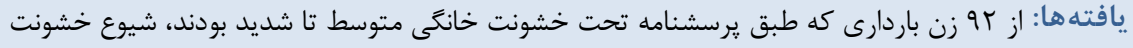

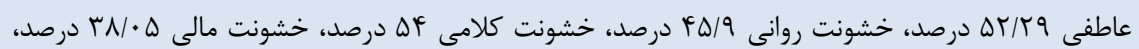
خشونت جسمى

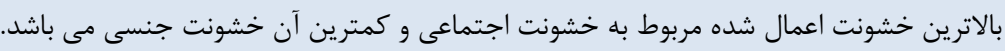

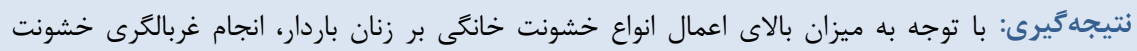

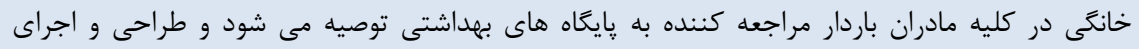

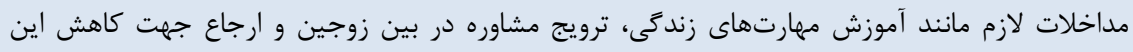

$$
\text { معضل در خانواده ها ضرورت دارد. ماند اموزت ملات }
$$

وازَّان كليدى: ز زنان باردار؛ خشونت خانكى؛؛ صحنه

خشونت جسمانى، روانى يا عاطفى، جنسى، اقتصادى و كلامى

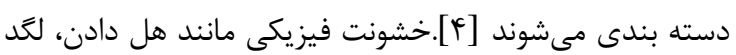

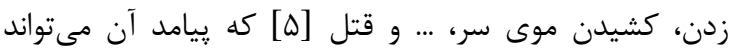

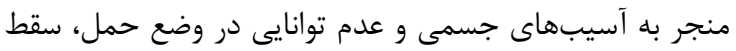

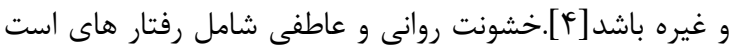

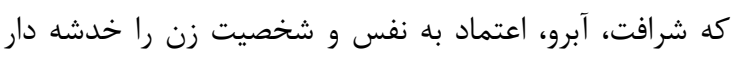

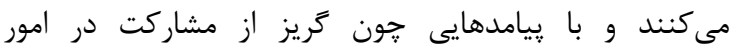

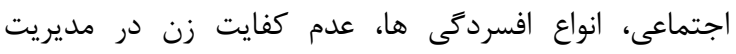

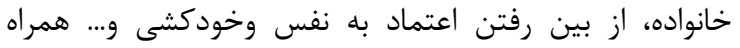

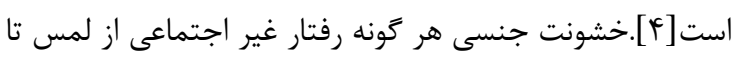

خشونت عليه زنان يكى از مشكلات مههم حقوق بشر در

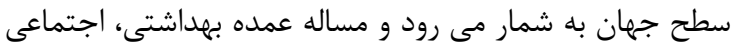

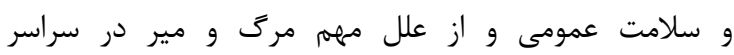

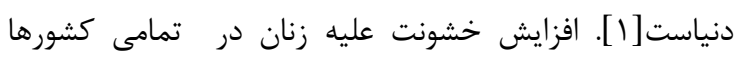

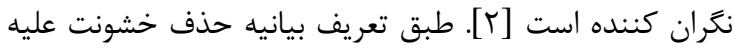

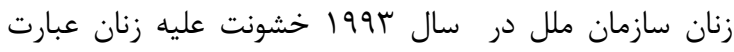

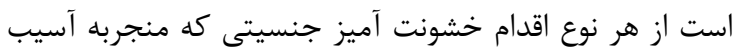

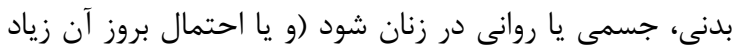

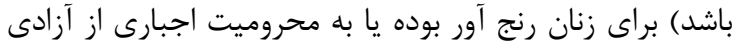

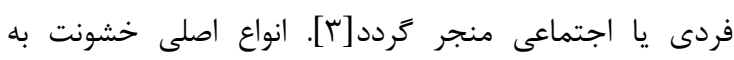


وزن نامناسب و وزن كم هنكام تولد، سقط، زايمان زودرس،

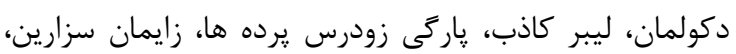

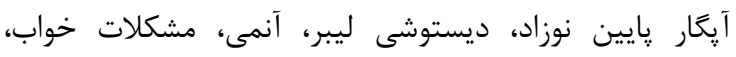

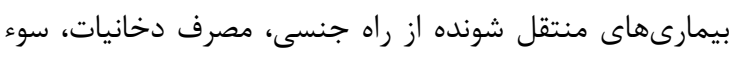

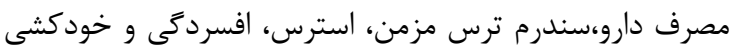

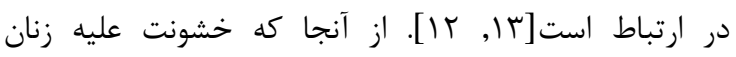

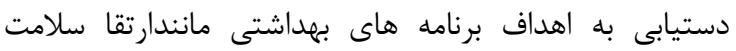

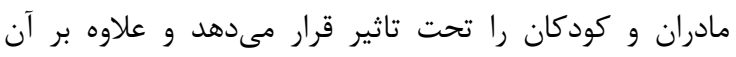

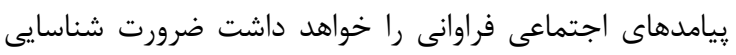

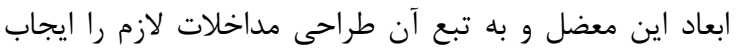

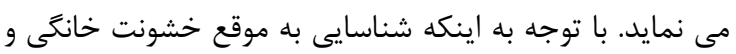

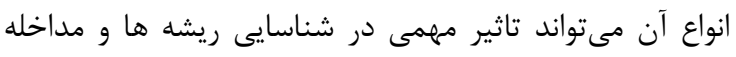

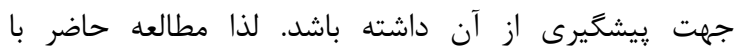

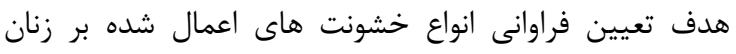
باردارشهرستان صحنه انجام كرديد.

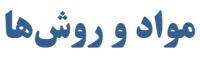

اين مطالعه يك يزوهش توصيفى از نوع مقطعى بود، كه

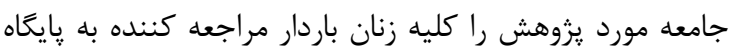

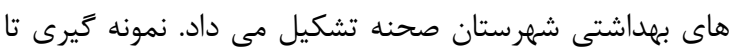

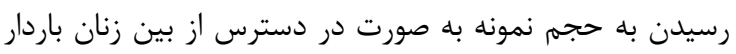

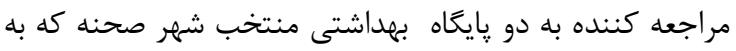
روش تصادفى (قرعه كشى) انتخاب شده بود، ادامه يافت. نهايتا

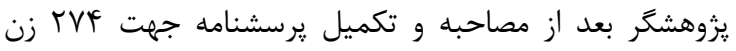

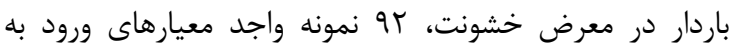

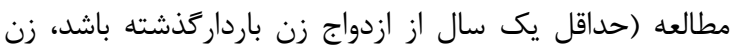

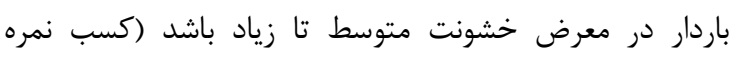

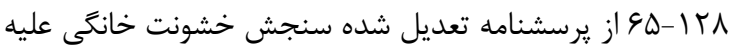

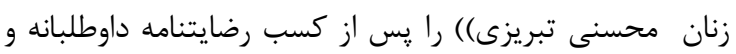

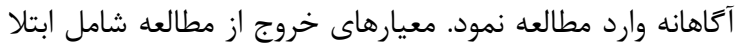

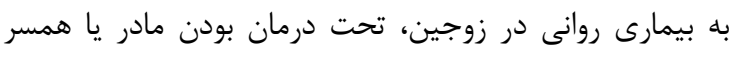

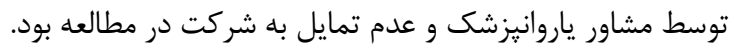

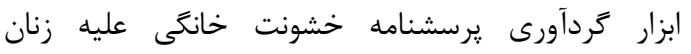
محسنى تبريزى و همكاران بود كه با استفاده از منابع معتبر

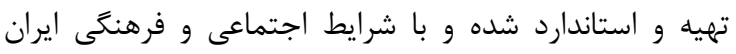

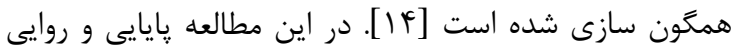

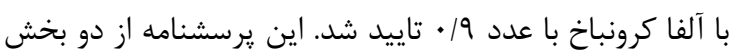

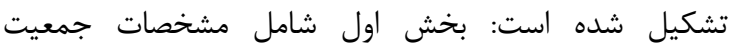

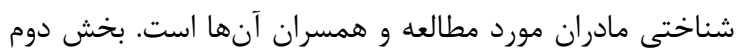

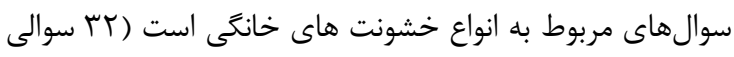

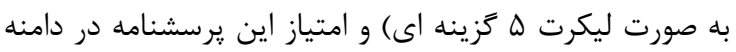

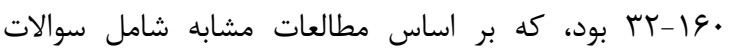
مربوط به خشونت هاى جسمى (9 سوال)، روانى (9 سوال)،

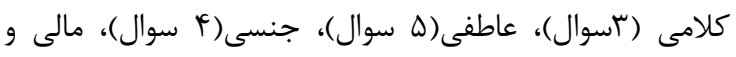

تجاوز را در بر مى كيرد و منجر به صدمات روانى، عصبى و

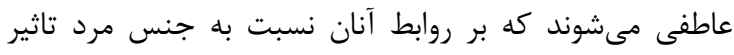

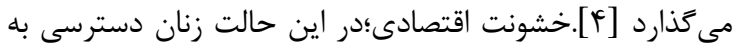

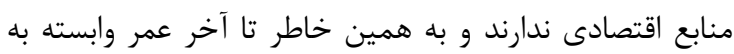

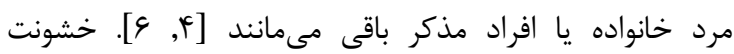

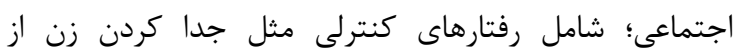

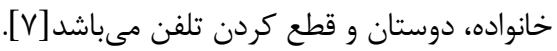

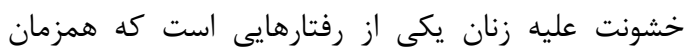

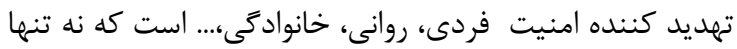

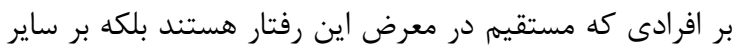

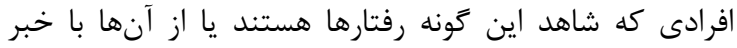

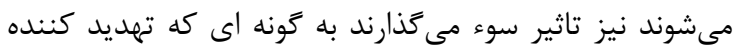

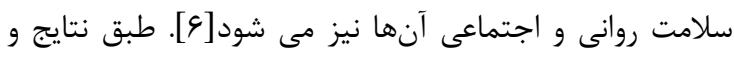

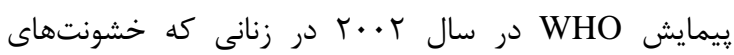

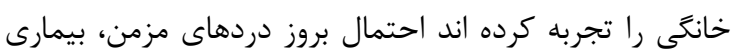

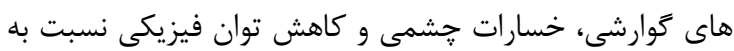

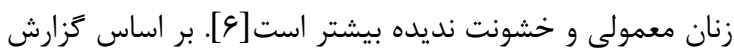

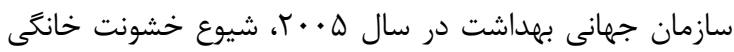

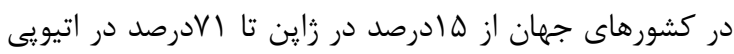

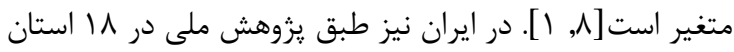

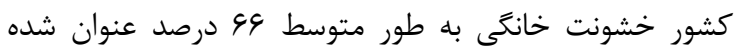

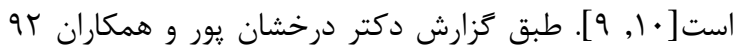

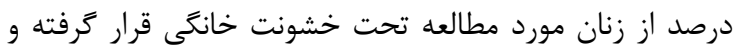

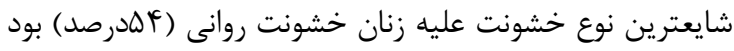

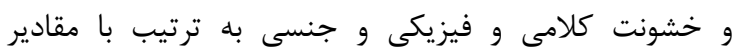

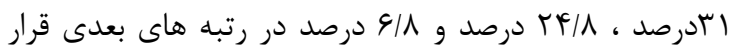

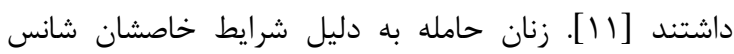
بيشترى براى خشونت دارند [V]]. باردارى به دلايلى مختلف

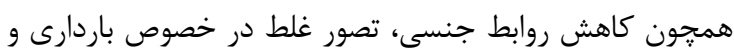

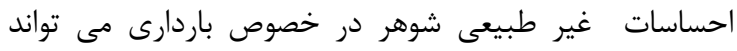

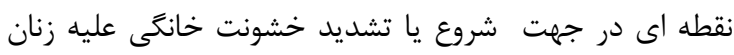

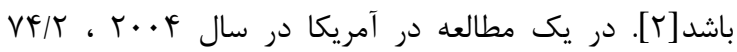

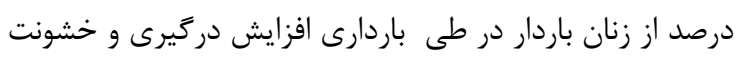

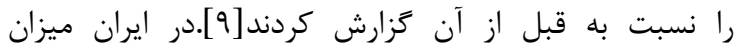

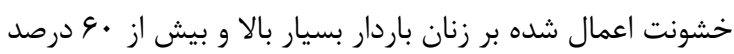

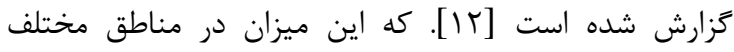

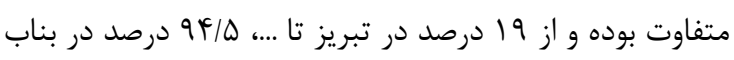
كزارش شده است. همجنين شيوع خشونت فيزيكى در دوران إدان

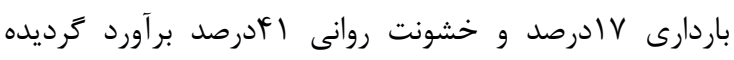

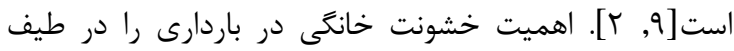

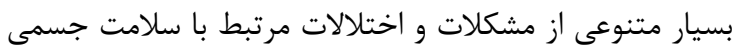

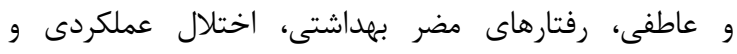

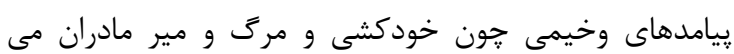

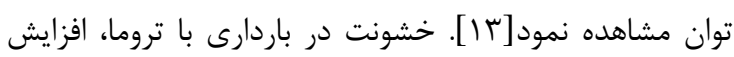


افراد كمتر از يك ميليون تومان در ماه درآمد داشتند. از نظر تحصيلات و • V درصد از مادران تحصيلات دانشخاهى نداشتند

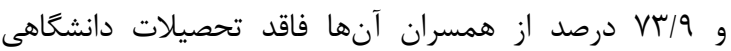

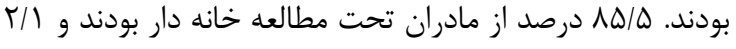

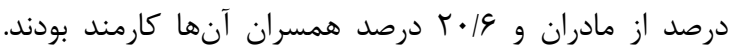

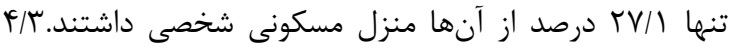
درصد از افراد تحت مطالعه جنسيت فرزند دلخواهشان نبود.

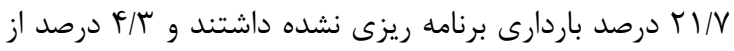
همسران آنها مصرف كننده مواد مخدر بودند (جدول برد برد). جدول ا: ميانگين سن مادر، سن همسر و مدت ازدواج زنان باردار در معرض خشونت

\begin{tabular}{|c|c|}
\hline ميانكين(سال)ـ انحراف معيار & 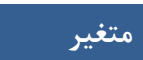 \\
\hline$r V / \Delta \Delta \pm \Delta / \varphi$ & 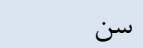 \\
\hline$T r / 9 \pm 9 / 1$ & سن همسر \\
\hline$q / 1 \pm r / \Lambda$ & مدت ازدواج \\
\hline
\end{tabular}

اجتماعى(r سوال) تنظيم شده است. يُوهشكر افرادى كه در معرض خشونت خانكى هستند و در طيف در معرض خشونت

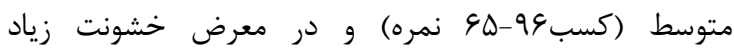

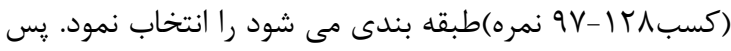

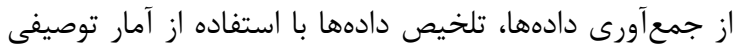

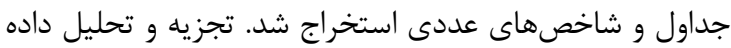
ها با استفاده از نرم افزار آمارى

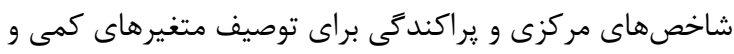
از جدول توصيف فراوانى براى متغيرهاى كيفى استفاده كرديد.

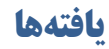

در اين مطالعه rو زن باردار در معرض خشونت متوسط تا شديد بررسى شدند. ميانگين سن مادران در اين مطالعه

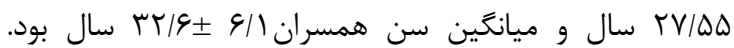

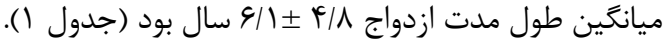

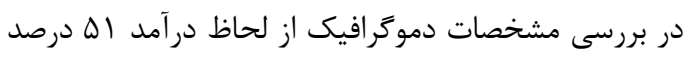

جدول ץ: توزيع فراوانى مشخصات دموگرافيك در زنان باردار در معرض خشونت

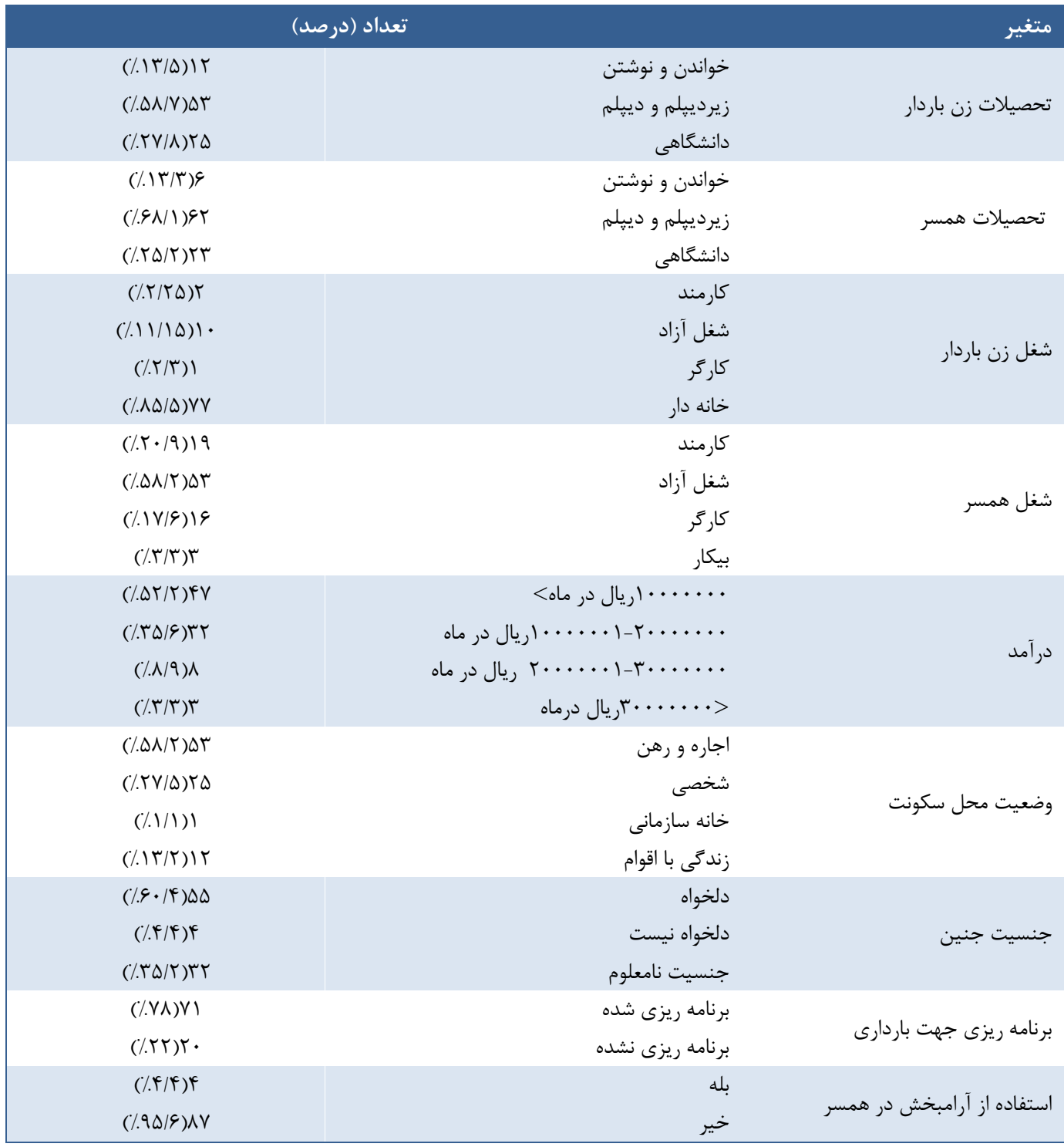


زوجين بدليل باردارى بوده و باعث به هم خوردن توازن و

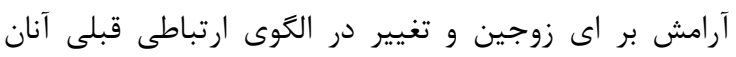

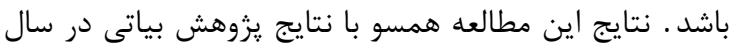

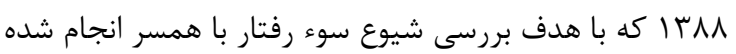

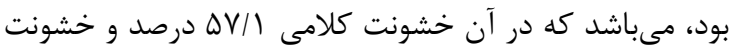

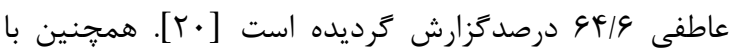

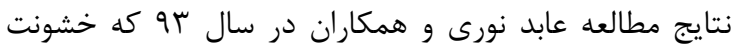

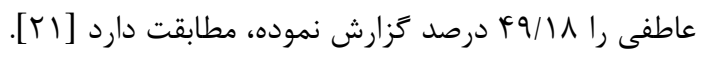

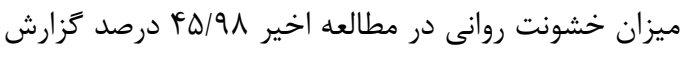

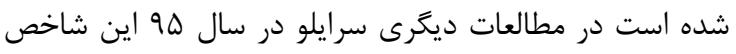

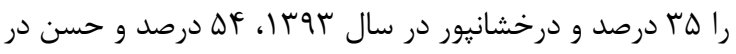

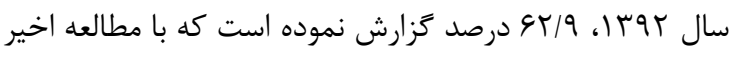

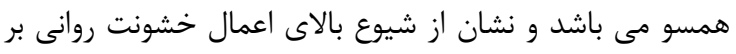

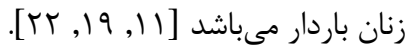

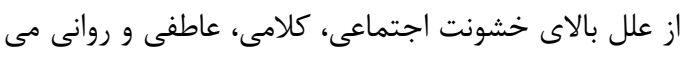

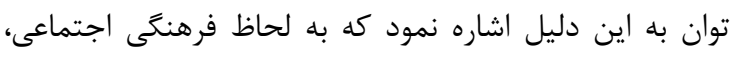

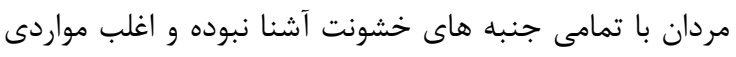

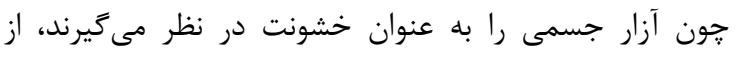

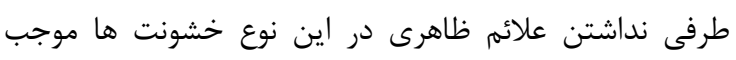

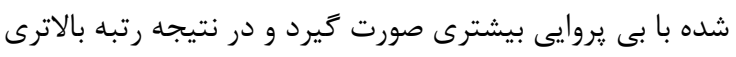

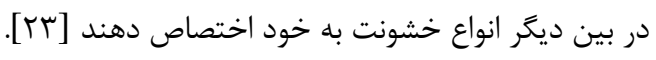

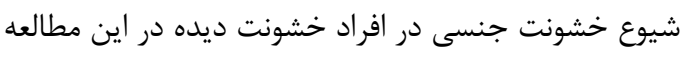

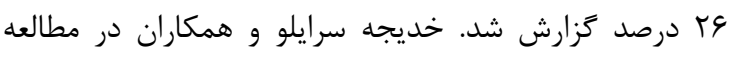

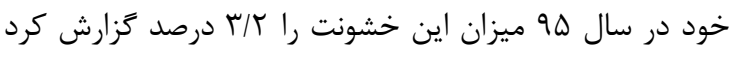

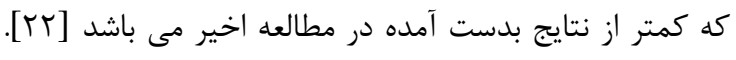

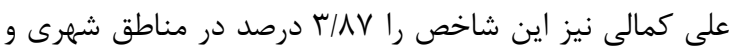

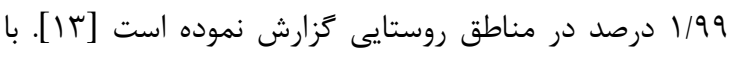

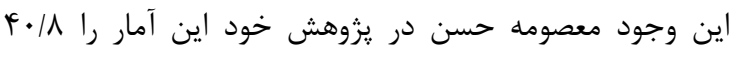

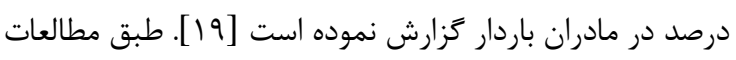

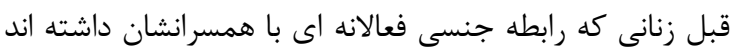

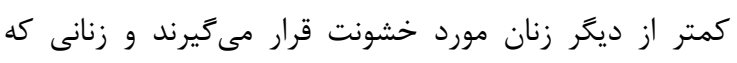

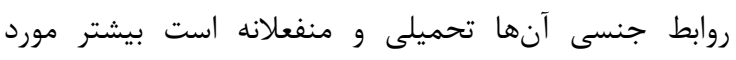

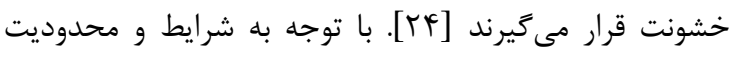

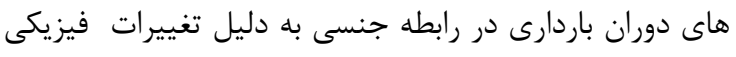

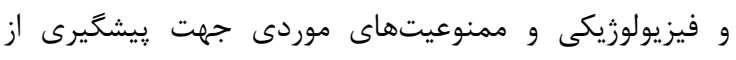

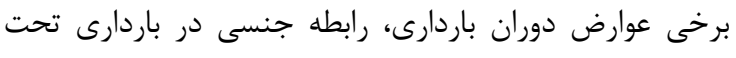

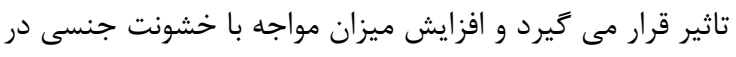

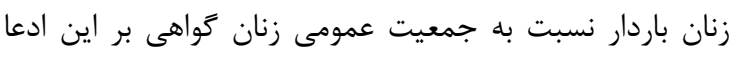

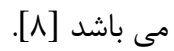
از ديكر جنبه هاى خشونت كه در اين مطالعه بر برسى شد،

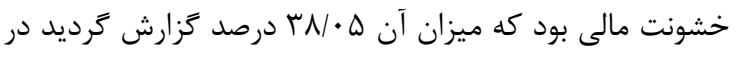

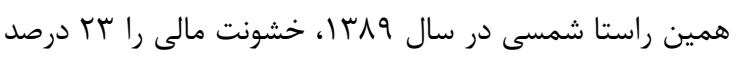

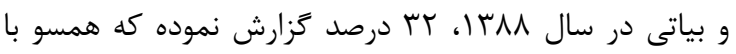

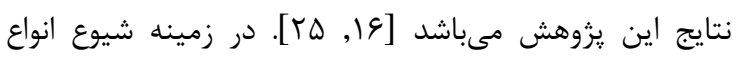

در جدول ب فراوانى انواع خشونت اعمال شده بر زنان باردار

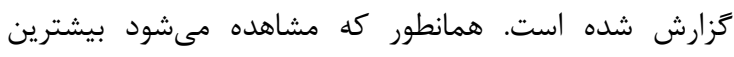

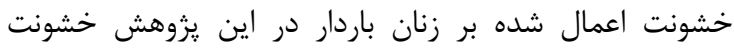

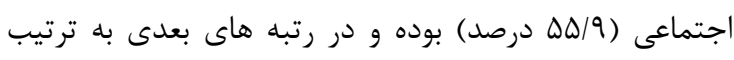

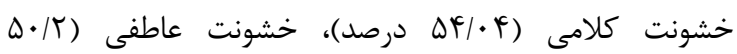
درصد)، خشونت روانى(

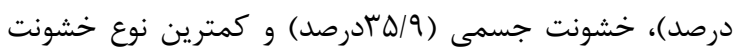

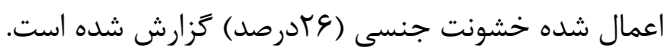

\begin{tabular}{|c|c|c|}
\hline درصد & تعداد & متغير \\
\hline$\Delta \cdot / T$ & 49 & خشونت عاطفى \\
\hline$F \Delta / 9$ & Fr & خشونت روانى \\
\hline$\Delta F / \cdot F$ & $4 q$ & خشونت كلامى \\
\hline$r N / \cdot \Delta$ & rF & خشونت مالى \\
\hline एब/৭६ & rז & خشونت جسمى \\
\hline re & $r$ & خشونت جنسى \\
\hline$\Delta \Delta / 9$ & $\Delta$. & خشونت اجتماعى \\
\hline
\end{tabular}

هدف اين يزوهش تعيين فراوانى حيطه هاى مختلف

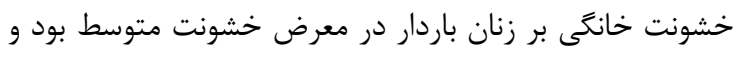

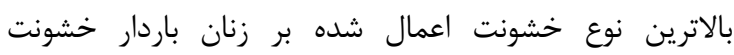

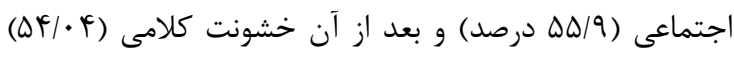

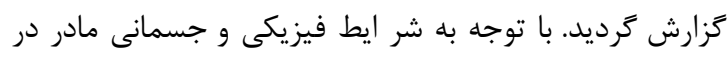

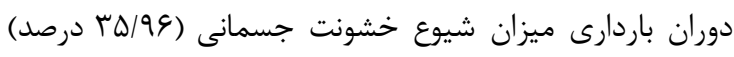

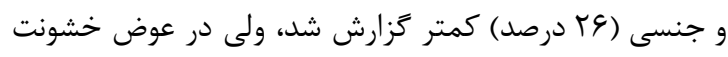

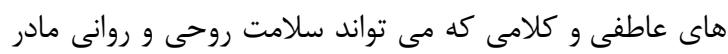
را به مخاطره اندازد، بيشتر بود.

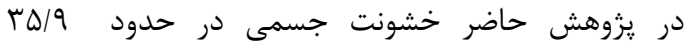

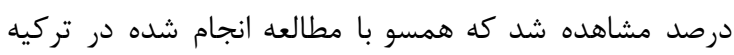

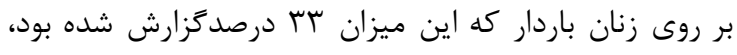

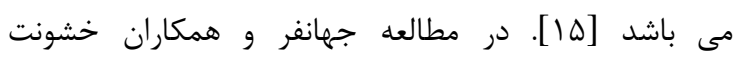

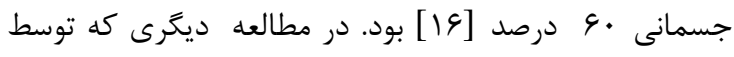

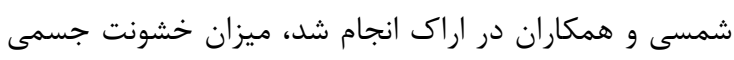

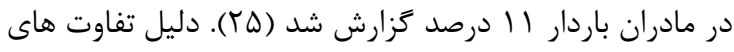

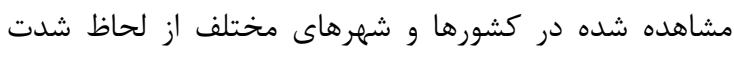

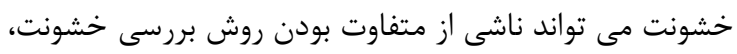

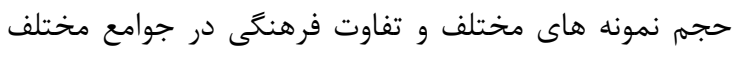

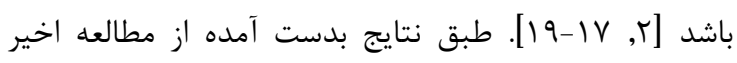

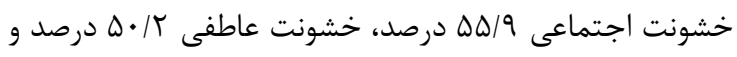

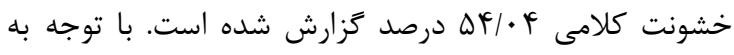

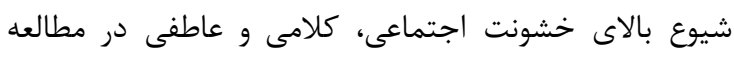

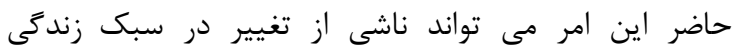


كودى متولد شده و در نهايت سلامت جامعه خواهد داشت. لذا تحقيقات گسترده در زمينه ريشه يابى و انجام مداخلات در درد جهت كاهش اين مشكل را مى طلبد.

\section{نتيجه تيرى}

انواع حيطههاى خشونت خانكى در مادران باردار شهرستان

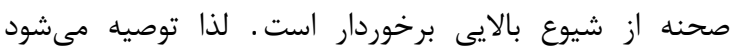

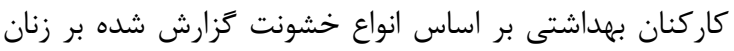

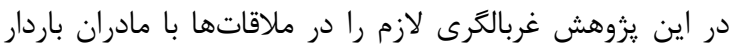

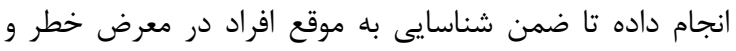

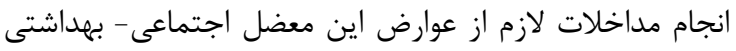

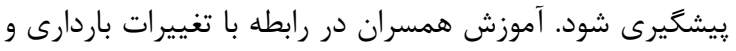
آموزش زوجين در خصوص مهارتهاى زندگىى، داشتن تعاملات

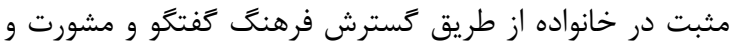

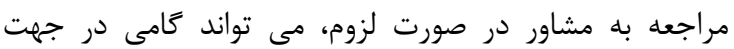
كاهش بروز اين معضل و عوارض ناشى از آن باشد.

\section{تشكر و قلرو فاذى}

اين مقاله بركرفته از پايان نامه دوره كارشناسى ارشد مشاوره در مامايى مصوبه شوراى يزوهشى دانشعاه علوم يزشكى داني

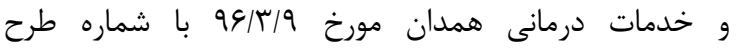

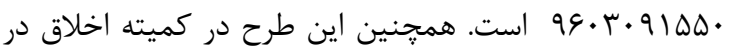

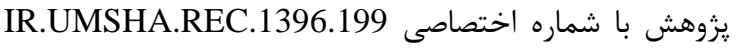

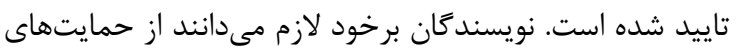

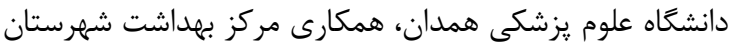

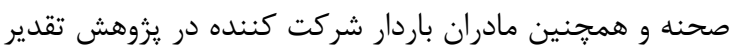

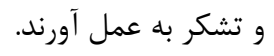

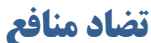
اين مطالعه براى نويسندگان هيجزونه تضاد منافعى نداشته

\section{REFERENCES}

1. Razaghi N, Parvizy S, Ramezani M, Tabatabaei Nejad SM. The consequences of violence against women in the family: a qualitative study. The Iranian Journal of Obstetrics, Gynecology and Infertility. 2013;16(44):11-20 .(Persian)

2. Karimi A, Daliri S, Sayehmiri K.The prevalence of physical and psychological violence during pregnancy in Iran and the world: A systematic review and meta-analysis. Journal of Clinical Nursing and Midwifery. 2016;5(3):73-88. (Persian)

3. Ahmadi B, Nasseri S, Alimohamadian M, Shams M, Ranjbar Z, ShariatM, et al. Views of Tehrani couples and experts on domestic violence against women in Iran: A qualitative research. Journal of School of Public Health and Institute of Public Health Research. 2008;6(2):67-81. (Persian)

4. Niazi M, Kassani A, Menati R, Khammarnia M .The prevalence of domestic violence among pregnant women in iran: A systematic review and meta-analysis. Sadra Medical Sciences Journal. 2017;3(2):139-150. (Persian)

5. Pourgaz A, Raghibi, Mahvash. Survey on the type and
خشونت خانكى نتايج متفاوتى در مناطق مختلف گزارش

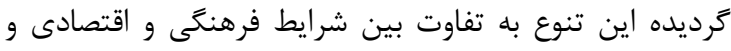

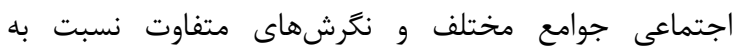

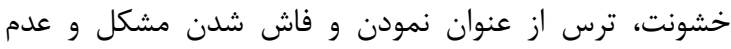

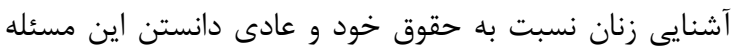

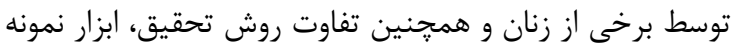

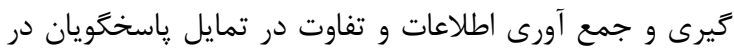

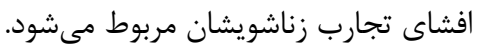

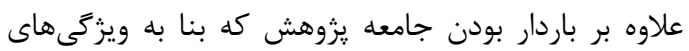

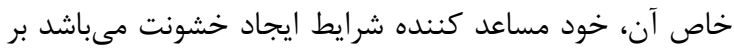

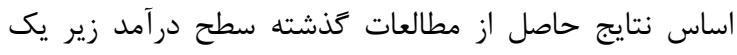

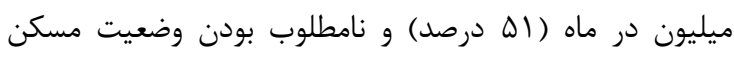

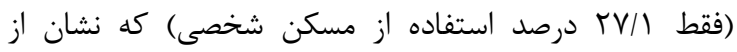

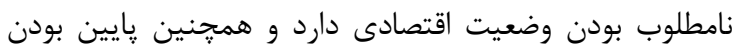

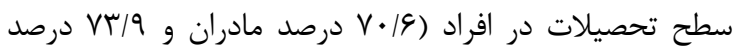

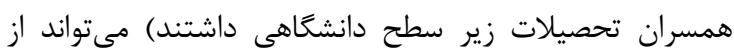

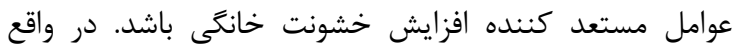

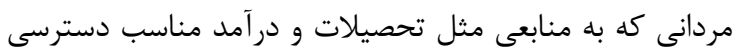

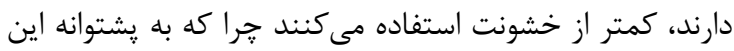

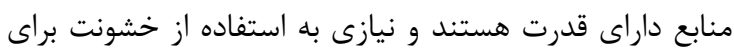

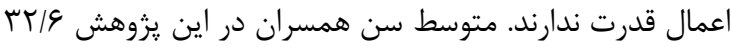

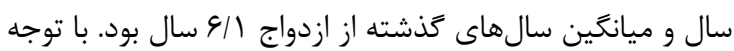
به اينكه در برخى مطالعات افزايش سن و كذشتن سالهاى سناى

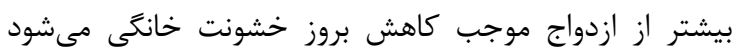

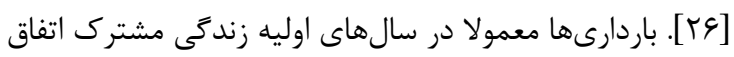

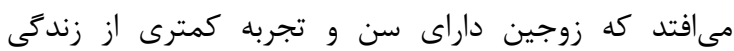

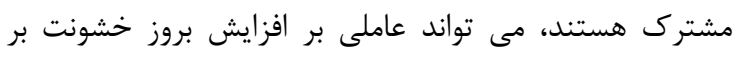
زنان باردار باشد.

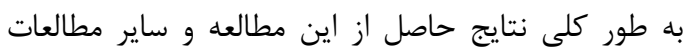

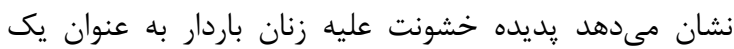

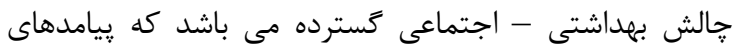

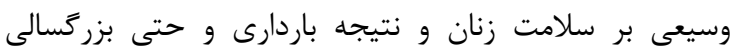

factors of domestic violence against women among Turkmen tribes in Golestan province. Journal of Educational Psychology Studies. 2005;1(1):73-96. (Persian)

6. Mohammadbeigi A, Seyedi S, Behdari M, Brojerdi R, Rezakhoo A. The effect of lifeskills training on decreaising of domestic violence and general health promotion of women. 2016; 13(10): 903-911. (Persian)

7. Mohamadi N, Shobeiri F, Khodaveisi M. A Survey on Physical Violence during Pregnancy. scientific journal of ilam university of medical sciences. 2012;20(3):3845.(Persian)

8. Vameghi M, Sajadi H, Rafiey H, Rashidian A. The socioeconomic status of street children in Iran: a systematic review on studies over a recent decade. Children \& Society. 2014;28(5):352-65. (Persian)

9. Khadivzadeh T, Erfanian F. Comparison of domestic violence during pregnancy with the pre-pregnancy period and its relating factors. The Iranian Journal of Obstetrics, Gynecology and Infertility. 2011;14(4):47-56. (Persian) 
10. Soodeh M, Fatemeh YN, Fatemeh E. Investigating factors influencing domestic violence against women (case study: city of Kerman). Social Development. 2015;9(3):53-78. (Persian)

11. Derakhshanpour F, Mahboobi H, Keshavarzi S. Prevalence of domestic violence against women. Journal of Gorgan University of Medical Sciences. 2014;16(1.:126-131. (Persian)

12. Golmakani N. Domestic violence in pregnancy, outcomes and strategies: a review article. The Iranian Journal of Obstetrics, Gynecology and Infertility. 2013;15(42):13-22. (Persian)

13. Kamali M, Rahimi Kian F, Mir Mohamad Ali M, Mehran A, Shafiei E. Comparison of domestic violence and its related factors in pregnant women in both urban and rural population in Zarand city, 2014. Journal of Clinical Nursing and Midwifery. 2015;4(2): 69-78. (Persian)

14. Mohseni TA, Kaldi A, Javadianzadeh M. The study of domestic violence in marrid women addmitted to yazd legal medicine organization and welfare organization. 201; 11(3):11-24. (Persian)

15. Johnson J, Haider F, Ellis K, Hay D, Lindow S. The prevalence of domestic violence in pregnant women. Bjog: An International Journal of Obstetrics \& Gynaecology. 2003;110(3):272-5.

16. Jahanfar S, Malekzadegan Z. The prevalence of domestic violence among pregnant women who were attended in Iran University of Medical Science Hospitals. Journal of Family Violence. 2007;22(8):643. (Persian)

17. Faramarzi M, Esmailzadeh S, Mosavi S. Prevalence and determinants of intimate partner violence in Babol City, Islamic Republic ofIran. East Mediterr Health J. 2005;11(56):870-9. (Persian)

18. Soleimani A, Khademi N, Ahmadi A, Delpisheh A, Jafarinia B, Sayehmiri K. Prevalence of Violence Against Women in
During Pregnancy in Iran: A Systematic Review And Metaanalysis. The Journal of Urmia Nursing and Midwifery Faculty. 2016;13(11):973-86. (Persian)

19. Hassan M, Kashanian M, Hassan M, Roohi M, Yousefi H. Domestic violence: prevalence during pregnancy and associated maternal outcomes. Urmia Medical Journal. 2014;24(11):894-903. (Persian)

20. Shamsi M, Bayati A. Frequency and severity of domestic violence in pregnant women. Journal of Gorgan University of Medical Sciences. 2011;13(4):67-75. (Persian)

21. Noori A, Sanago A, Jouybari L, Azimi M. Survey of types of domestic violence and its related factors in pregnant mothersin Kalaleh at 2014. The Iranian Journal of Obstetrics, Gynecology and Infertility. 2017;19(39):54-62. (Persian)

22. Srailoo, Abadi N, Mirzaie K, Ranjbar, Moghadam B. Surveying the Prevalence of Domestic Violence in Pregnant Women and Related Factors. Iran Journal of Nursing (20085923). 2017;29(104): 54-62. (Persian)

23. Torkashwand F, Rezaeean M, Sheikhfathollahi M, Mehrabian M, Bidaki R, Garousi B, et al. The Prevalence of the types of domestic violence on women referred to health care centers in Rafsanjan in 2012.Journal of Rafsanjan University of Medical Sciences. 2013;12(9):695-708. (Persian)

24. Raisi T. The roots of violence against women in the family. J Fam Res. 2012;8(1):7-18. (Persian)

25. Shamsi M, Bayati A, Mohamadbeygi A, Tajik R. The effect of educational program based on Health Belief Model (HBM) on preventive behavior of self-medication in woman with pregnancy in Arak, Iran. Pejouhandeh. 2010;14(6):324331. (Persian)

26. Salarifar M. Explaining the causes and context of domestic violence. Biquaterly journal of studies in islam\& psychology. 2009;3(4):7-41. (Persian) 